\title{
Translation of Culture Specific Items: A Case Study of Persian Architecture Terminology
}

\author{
Esmaeil Bagheridoust \\ Faculty of Persian Literature and Foreign Languages, Islamic Azad University South Tehran Branch, Iran \\ E-mail: e_bagheri@azad.ac.ir \\ Zahra Mahabadi Mahabad (Corresponding author) \\ Faculty of Persian Literature and Foreign Languages, Islamic Azad University South Tehran Branch, Iran \\ E-mail: Zahramahabadmahabadi@gmail.com
}

Received: 08-09-2016

Published: 01-03-2017
Accepted: 15-11-2016

doi:10.7575/aiac.ijalel.v.6n.2p.46
Advance Access Published: January 2017

URL: http://dx.doi.org/10.7575/aiac.ijalel.v.6n.2p.46

\begin{abstract}
Architectural texts involve a great deal of CSIs that reflect the culture of a country. Translating these CSIs from Persian into English seems one of the key issues in the translation of architectural texts. This source-oriented descriptive study tried to investigate CSIs of the Persian architecture in order to examine the extent to which the translators/writers have succeeded in rendering CSIs, while translating them from Persian architecture into English or writing on the Persian Architecture in English. In addition, it tried to investigate the most frequently used strategies by writers/translators according to Van Doorslaer's (2007) model. To serve research purposes, two textbooks on Iranian architecture (i.e., Introducing Persian Architecture by Pope and Abbasid Guest House by Ouliaienia) were sampled. The findings indicated that the translator (Ouliaienia) and the writer (Pope) were successful in finding appropriate equivalents for SL architectural terms. The comparison of Pope's textbook and Ouliaienia's translation demonstrated that they had made use of four of the strategies (i.e., Direct Transfer, Word for Word Translation, Interpretation, and Domestication). Accordingly, in pope's book, Interpretation was the most frequently used strategy, while Direct Transfer was the most frequently utilized one in Ouliaienia. On the other hand, Word for Word Translation was the least frequently used strategy in Pope's work, whereas Domestication was the least frequently utilized one in Ouliaienia's work. The findings of the present study may have some significant implications for translation theory and practice.
\end{abstract}

Keywords: Translation, CSIs, Persian Architecture, Terminology

\section{Introduction}

Culture is one of the most important elements in architecture as it has been described. Different cultures have different manifestations. In other words, some concepts and items are bound to a specific culture and country and do not exist in any other (Terestyényi, 2011). Therefore, it is important to understand these items in order to translate or even write about them. These are called culture specific items (CSI).

Culture Specific Items (CSIs) are those that do not exist in the target text or have a different inter-textual status. Translators or even writers confront difficulties in translating these items. According to Aixela (1996), a CSI does not exist by itself, but it is the result of transferring the source text to the target text that poses translation difficulty due to the non-existence of or to the different value of the given item in the target language culture.

Architecture of Persia is abundant with culture specific items. Due to the cultural differences and the meaning behind the strings of these culture specific terms, translating them from Persian into English seems challenging task for the translators (Ghobadi, 2013). When translating or writing text on the culture bound architecture, i.e. Persian architecture in this research, translators, or writers will confront difficulties, because they should use a proper equivalent for the CSI in their texts. Therefore, the purpose of the present study was two-fold. The first purpose was to see whether English writers and Persian-to-English translators of architectural textbooks have been successful in finding equivalents for culture-specific items (CSIs) in introducing Persian architecture. The second purpose was to determine the most frequently used strategies that writers and translators make use of in their attempts to find equivalents for CSIs in Persian architecture. Therefore, this research can be useful for non-Iranian students who are studying Persian architecture, in order to read and understand Persian architectural books in English. Secondly, this study can be useful for translators who want to translate architectural texts particularly Persian architecture. Thirdly, it can be useful for both architects and English teachers in order to teach the culture-specific items of Persian architecture and the meaning behind the string of these culture specific items for the students.

To achieve the objectives of this study, this researcher tried to answer the following three questions: 
RQ 1: To what extent have English writers succeeded in using the most natural equivalents of the CSIs in Persian architecture?

RQ 2: To what extent have Persian-to-English translators succeeded in using the most natural equivalents of the CSIs in Persian architecture?

RQ 3: Which strategies have been most frequently used by writers/translators in textbooks on Persian architecture according to Van Doorslaer's model (2007)?

\section{Methodology}

This research was a descriptive quantitative research that evaluated renderings of culture specific items in texts on Persian architecture and a case study was implemented on translating architectural culture specific items from Persian into English.

To serve the two research purposes, two textbooks on Iranian architecture were sampled. The first textbook was Introducing Persian Architecture written by Arthur Upham Pope (1965) in English. This textbook was selected as the sample of the present study to see how an English writer has faced the challenge of CSIs in Persian architecture. The second textbook was Hotel Abbasi written by Borjian and Borjian (1997) in Persian. The textbook was later translated into English by Ouliaienia (1997). Ouliaienia's translation of Hotel Abbasi (i.e., Abbasid Guest House) was sampled as the second textbook to see how a Persian-to-English translator has faced the challenge of CSIs in Persian architecture.

Among many architectural books related to Persian architecture in Persian and English, there were a few books translated and consequently available in both languages. In addition, among those translated books, only some of them were related to the issue of the present research, because many of them did not include CSIs. Therefore, this research was delimited to the two above-mentioned books on Persian architecture that is written in English and translated into English. In addition, the present research was delimited to culture-specific items in the two books.

To achieve the objectives of this research, the following steps were taken to analyze the translation of culture specific items in architectural text chosen:

1. The chosen source texts were read line by line to find the culture specific items. To achieve the aims of this research, some instruments were required, including Visual Dictionary of Architecture written by Ching (2011), which later translated into Persian by Mohammad Ahmadinejad and glossary of Persian Architecture by Rafiee Sereshki, Rafizade, Ranjbar Kermani (2007). These two glossaries were used as the points of reference to examine the rendering of CSIs in Persian Architecture.

2. As the next step, the rendering of culture specific items was extracted carefully from the textbooks in order to determine to what extent English writers/Persian-to-English translators have succeeded in using the most natural equivalents of the CSIs in Persian architecture.

3. Then, we did our best to examine which strategies have been most frequently used by writers/translators in textbooks on Persian architecture according to Van Doorslaer's model (2007)?

It is noteworthy that to analyze the findings of this study, the present researcher has chosen the strategies of Van Doorslaer's (2007) model, because it introduces the following relevant and possible strategies to find a proper equivalent for CSIs:

1. Acculturation

2. Amplification

3. Calque

4. Compensation

5. Condensation

6. Direct transfer

7. Expansion

8. Implicitation

9. Interpretation

10. Modification

11. Recategorization

12. Adaptation

13. Borrowing

14. Coinage

15. Concision

16. Denominalization

17. Dilution

19. Interchange 
20. Modulation

21. Paraphrase

22. Reformation

23. Omission

The chosen strategies were based on the data extracted from the source books. According to the rendering of CSIs, strategies such as domestication, direct transfer, word for word translation or calque and interpretation were used to achieve the objectives of this research.

As previously mentioned, it was a comparative descriptive research in which the source texts and the target texts were examined in order to find CSIs in Persian architecture. Then, the CSIs were compared in both ST and TT and the most frequently applied strategies were determined. Based on the research questions and the mentioned procedures, this study was source-oriented descriptive research in which the chosen strategies by the translator/writer based on Van Doorslaer's (2007) model were investigated. This study on two case studies of Persian Architecture was restricted to the lexical choices regarding culture specific items. In addition, this research examined which strategies have been used mostly by the writer and translator.

Despite all the limitations ahead of this research to find the data, we selected two materials that have enough number of CSIs, and all words were extracted from them (i.e., Introducing Persian Architecture by Pope (1965) Abbasid guesthouse by Borjian and Borjian (1997)). Therefore, all words were originally extracted from these two books, no changes were made in order to achieve the objectives, and no data was fabricated to answer the research questions.

\section{Results}

As previously mentioned, the present study tried to investigate how an English writer (Pope) and a Persian-to-English translator (Ouliaienia) have rendered CSIs in their textbooks on Persian architecture. The analysis of Pope's Introducing Persian Architecture and Ouliaienia's translation of Hotel Abbasi indicated that Pope (1965) and Ouliaienia (1997) have avoided the use of strategies that are inappropriate for rendering CSIs. The criterion set for inappropriacy of strategies was that they are strategies that the writer/translator resorts to when he/she fails to find appropriate equivalent for a CSI (Dimitriu, 2004). Examples of inappropriate strategies for CSIs in Van Doorslaer's (2007) theoretical framework are Coinage, Paraphrase, Reformation, and Omission. For example, in the case of Omission, the translator totally disregards a CSI, because he/she cannot find an equivalent for it (Dimitriu, 2004).

Fortunately, neither Pope (1965) nor Ouliaienia (1997) have made use of these strategies in their works. To be more specific, Pope (1965) and Ouliaienia (1997) have only made use of four strategies that are the most frequently used strategies for rendering CSIs (i.e., Direct Transfer, Word for Word Translation, Interpretation, and Domestication).

\subsection{Direct Transfer}

According to Vinay and Darbelnet (1997), in the strategy of Direct Transfer (also known as Borrowing), a source language (SL) item is transferred directly to the target language (TL). The following is an example of the strategy of Direct Transfer extracted from Abbasid Guest House:

\section{Example 1:}

اما شاخص ترين بناى آن دوره مجمو عه كاروان سراست.

(Borjian \& Borjian, 1997, p.49)

English Translation: Yet the most distinguished monument of that era is the complex of caravansaries. (Ouliaienia, 1997, p. 49)

In Pope's Introducing Persian Architecture, the history of caravanserai is believed to be originated in Persian architecture and goes back to Akhaemanid era. According to Rafiee Sereshki, et al. (2007), the history of caravansaries goes back to Akhaemanid era in Persian architecture. In fact, caravanserai is an area in roads where travelers can rest and recover from the day's journey. The Persian word caravanserai or carevansary is a compound of Karavan and Sara (i.e., palace, building with enclosed courts). The word "caravan" means a group of traders, pilgrims or other travelers who go to long-distance travels. As you see in above example, the word /karevansæra/, as a CSI in Persian architecture, has been directly transferred from the SL (Persian) into the TL (English) by Ouliaienia (1997). Thus, Ouliaienia (1997) has utilized Direct Transfer Strategy in her translation for rendering this CSI.

The following is another example of the strategy of Direct Transfer, this time in Pope's (1965) Introducing Persian Architecture:

Example 2 : Bad gīr are tall square towers with open vents on each side to catch any cooling breathe of air and carry it down to the recesses of the house (Pope, 1965 , p. 245)

/Bad gīr/ is a traditional Persian architectural element to create natural ventilation in buildings. It seems that bad-gīr is a specification of Persian architecture that has been invented in Persia and does not exist in other architecture constructions in other cultures (Rafiee Sereshki, et al., 2007). Therefore, Pope (1965) has transferred this term directly while writing on this CSI in his book. 


\subsection{Interpretation}

The strategy of Interpretation involves the elaboration of a CSI from the SL in the TL because of the fact that the CSI belongs to the SL culture with no counterpart in the TL culture (Vinay \& Darbelnet, 1997). The following is an example in which Pope (1965) has made use of the Interpretation Strategy to render a CSI from Persian architecture:

Example 1: Identical wide half octagon porches on the north and south sides have high roofs supported by exceedingly tall and slender columns originally faced with mirrors (Pope, 1965, p. 231).

"Hashti", in the traditional architecture of Iran, is the space behind the sar-dar (i.e., doorway). Hashties are designed in many different shapes, including octagonal, hexagonal, square and rectangular (Rafiee Sereshki, et al., 2007). In luxurious homes in the Ancient Iran, Hashti had more ornamentation and a seating area. As you see in the above example, Pope (1965) has used the strategy of Interpretation for rendering "Hashti" into the English language, because this item exists in Persian architecture terminology, but it seems that this CSI does not exist in any other culture including the English language culture. In other words, the word /Hashti/ has been illustrated as it looks like in its shape as "identical wide half octagon porches".

\section{Example 2:}

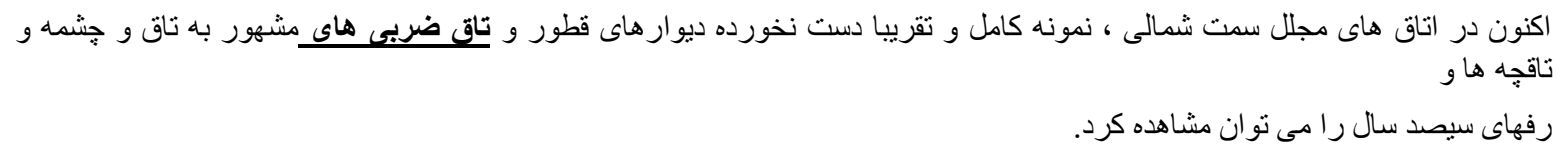

(Borjian \& Borjian, 1997, p. 5)

English Translation: today, in the magnificent northern rooms, samples of thick and almost untouched walls, vaults known as arches, the niches and the shelves of three hundred years can be still seen here. (Ouliaienia, 1997, p. 5)

The CSI of /taq zarbi/ has been elaborated through the strategy of Interpretation in both Pope's (1965) book and Ouliaienia's (1997) translation but via different words. By explaining how this culture-specific architectural construction would be built, Pope (1965) has in fact used the strategy of interpretation in his English book. Ouliaienia (1997) has utilized the same strategy, albeit through different wordings, in his English translation of Hotel Abbasi.

\subsection{Domestication}

According to Venuti (1995, p. 20), the strategy of Domestication designates the type of translation in which a transparent fluent style is adapted to minimize the strangeness of the foreign text for the TL readers. For a better understanding of this strategy, look at the following example:

Example 1: A dome on squinches placed over a square formed by four large piers connected with arches.

(Pope, 1965, p. 21)

The word "squinch" comes from the Persian word 'sekonj'. According to Rafiee Sereshki, et al. (2007), a squinch in architecture is a construction filling in the upper angles of a square room to form a base to receive an octagonal or spherical dome. The dome chamber in the palace of Ardeshir, the Sassanid king, in Firuzabad is the earliest example of the squinch (Rafiee Sereshki, et al., 2007). After the rise of Islam, squinch was used in the West Asia in both the Eastern Romanesque and Islamic Architecture (Rafiee Sereshki, et al., 2007). It has now remained as a feature of Islamic architecture, especially in Iran, and has been often covered by corbelled stalactite -like structures known as Muqarnas. Through Iran, squinch was spread to the Romanesque architecture of the Western Europe, one example being the Normans 12th century church of San Cataldo, Palermo in Sicily (Rafiee Sereshki, et al., 2007). 'Squinch' is the word used in Pope's (1965) Introducing Persian Architecture to explain the specifications of what is known in Persian as "gushvareh". Therefore, the author has used the strategy of Domestication to express this CSI.

A comparison was done on how the word "taq" had been used in Pope's (1965) book and Ouliaienia's (1997) translation. For explaining the word /taq/ or vault, the strategy of Domestication has been used in both Pope's (1965) book and Ouliaienia's (1997) translation.

Example 2:

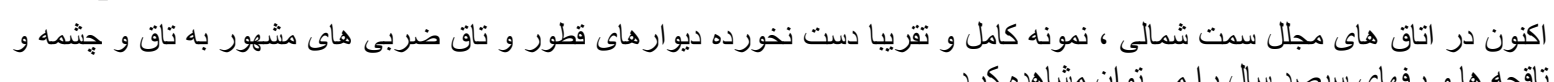

(Borjian \& Borjian, 1997, p. 5)

English Translation: today, in the magnificent northern rooms, samples of thick and almost untouched walls, vaults known as arches, the niches and the shelves of three hundred years can be still seen here. (Ouliaienia, 1997, p. 5) 
As you saw in Example 2, Pope (1965) has used the strategy of Domestication to explain what is known in Persian architecture as /taq/ and has used the word "vault" for this purpose. In a similar vein, Ouliaienia (1997) has used the same strategy to translate the respective CSI from Persian into English in his translation of Hotel Abbasi.

\subsection{Literal Translation or Word for Word Translation}

According to Vinay and Darbelnet (1997, p. 56), Literal Translation (also known as Word for Word Translation) is the prescription for good translation: literalness should be only sacrificed because of structural and metalinguistic requirements and only after checking that the meaning is fully preserved. For a better understanding of this strategy, several examples from the textbooks investigated in the presented study have been given below.

Example 1: dams for flooding flat areas, storage tanks, and deep wells strung along the desert routes made these difficult routes passable. (Pope, 1965, p. 246)

The history of water supplies goes back to 3500 years ago in the Ancient Persia and the first known of them is located in Chughazanbil in Susa. A water supply is a traditional reservoir of drinking water in Persian antiquity. The material used for constructing /ab anbars/ is /sarooj/ that is made of sand, clay, egg white, lime, goat hair, and ash. The construction is a tough and resistant to earthquake and it is also resistant to water penetration. As you see in the above example, Pope (1965) has utilized the strategy of Word for Word Translation for rendering this CSI into the English language.

Example 2:

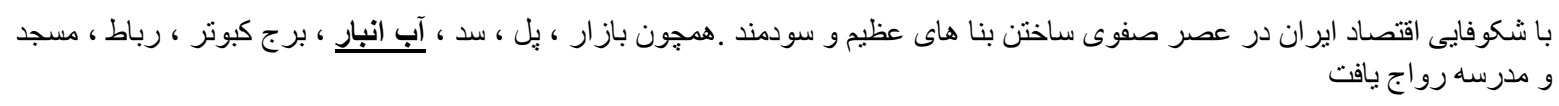

(Borjian \& Borjian, 1997, p. 35)

English Translation: Along with economic prosperity in the Safavi age, the construction of utilitarian monument such as bazaars, bridges, dams, pigeon towers, water supplies, inns, mosques, and schools was the vague of the time. (Ouliaienia, 1997, p. 35)

In a similar vein, Ouliaienia (1997) has used Word for Word Translation for rendering /ab anbar/ into /water supplies/.

As previously mentioned, the second purpose of the present study was to determine how frequently Pope (1965) and Ouliaienia (1997) have made use of the used strategies in their own works on Persian architecture. As mentioned earlier, Pope and Ouliaienia have only made use of four of the strategies listed in Van Doorslaer's (2007) theoretical framework of translation strategies (i.e., Direct Transfer, Word for Word Translation, Interpretation, and Domestication). Table 1 shows the frequency of these strategies as used by Pope (1965) in his Introducing Persian Architecture for rendering CSIs in Persian architecture. Table 2 indicates the frequency of the same strategies as used by Ouliaienia (1997) in the translation of Hotel Abbasi (i.e., Abbasid Guest House) to translate architectural CSIs from Persian into English.

Table 1. Strategies Applied for Rendering CSIs in Introducing Persian Architecture by Pope (1965)

\begin{tabular}{lll}
\hline \multirow{2}{*}{ Translation Strategy } & Pope (1965) & \\
\cline { 2 - 3 } & Frequency & Percentage \\
\hline Direct Transfer & 11 & $13.75 \%$ \\
\hline Word For Word Translation & 10 & $12.5 \%$ \\
\hline Interpretation & 37 & $46.25 \%$ \\
\hline Domestication & 22 & $27.5 \%$ \\
\hline Total & 80 & $100 \%$ \\
\hline
\end{tabular}

According to the information provided in Table 1 and Figure 2, the strategy of Interpretation has been used most frequently in Pope's (1965) textbook for rendering CSIs of Persian architecture. Pope (1965) has used this strategy 37 times (i.e., 46.25 percent). The second-ranked strategy in Pope's (1965) textbook is the strategy of Domestication that has been used 22 times (i.e., 27.5 percent) by the writer. In addition, the strategy of Direct Transfer has ranked third in the table with a frequency of 11 times (i.e., 13.75 percent). Finally, the strategy of Word for Word Translation is the least used strategy in Pope's (1965) Introducing Persian Architecture which has been used 10 times (i.e., 12.5 percent). 


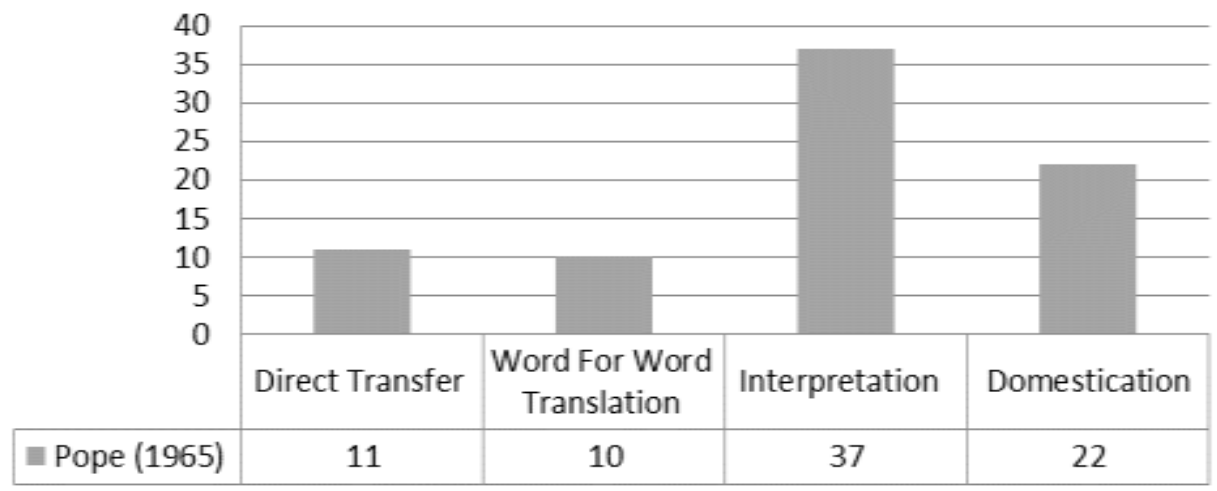

Figure 1. Strategies Applied for Rendering CSIs in Introducing Persian Architecture by Pope

Table 2. Translation Strategies Applied in Ouliaienia's Abbasid Guest House

\begin{tabular}{lll}
\hline \multirow{2}{*}{ Translation Strategy } & \multicolumn{2}{l}{ Ouliaienia (1997) } \\
\cline { 2 - 3 } & Frequency & Percentage \\
\hline Direct Transfer & 12 & $35.28 \%$ \\
\hline Word For Word Translation & 5 & $14.28 \%$ \\
\hline Interpretation & 11 & $31.42 \%$ \\
\hline Domestication & 7 & $20 \%$ \\
\hline Total & 35 & $100 \%$ \\
\hline
\end{tabular}

According to the information provided in Table 2 and Figure 2, the strategy of Direct Transfer has been used most frequently in Ouliaienia's (1997) translation of Hotel Abbasi (i.e., Abbasid Guest House) with the frequency of being used 12 times (i.e., 35.28 percent). The second-ranked strategy in Ouliaienia's (1997) translation of Hotel Abbasi is the strategy of Interpretation that has been used 11 times (i.e., 31.42 percent). In addition, the strategy of Domestication has ranked third with a frequency of 7 times being used (i.e., 20 percent). Finally, in Ouliaienia's (1997) work, the strategy of Word for Word Translation is the least used strategy that has been used 5 times (i.e., 14.28 percent).

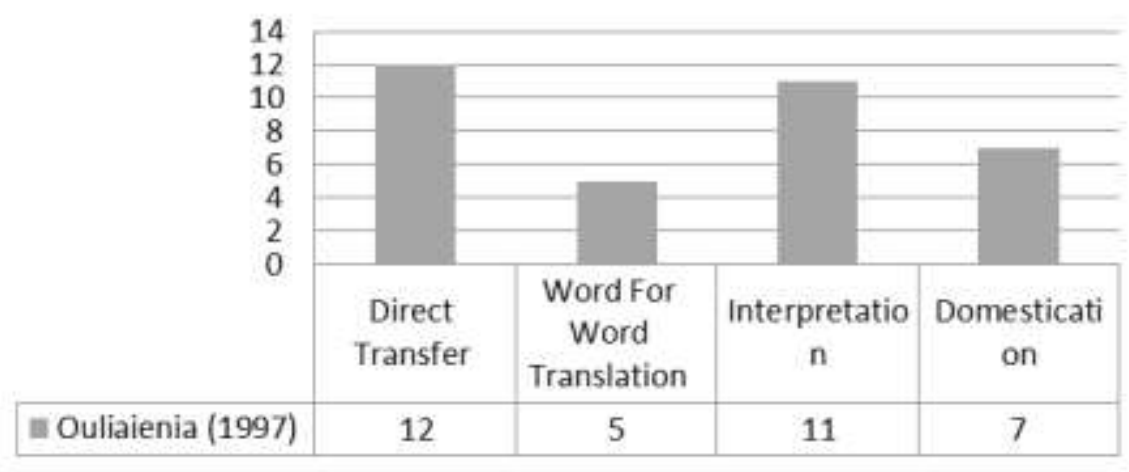

Figure 2. Strategies Applied for CSIs in Ouliaienia's Abbasid Guest House

\section{Discussion}

Culture specific items (CSIs) have always been an important issue in theory and practice in the field. Researchers contend that CSIs is where writers/translators have to make important decisions on the selection of strategies. Consequently, researchers have strongly argued, and found, that CSIs pose a challenging task to the writer/translator (e.g., Aixela, 1996; Baker, 1992; Kwiecinski, 1998).

The first and second research questions of the study aimed to determine to what extent writers and translators have succeeded in using the most natural equivalents for the CSIs in the Persian architecture. The criterion for determining whether Pope and Ouliaienia have been successful in findings appropriate equivalents for CSIs in their works was based on the strategies used. Some of the categories listed in Van Doorslaer's (2007) theoretical framework are ones that seem inappropriate for CSIs.

First, these inappropriate strategies are strategies the writer or the translator resorts to when he/she fails to trace appropriate equivalents for CSIs. There is a possibility that this situation would also happen in the case of architectural terms as these terms are highly bound to the society's cultural patters and, thus, it may be difficult to find appropriate equivalents for them in the TL. 
Of the strategies listed in Van Doorslaer's framework, Borrowing, Coinage, Paraphrase, Reformation, Omission, etc. are usually considered as strategies resorted to when there is no other choice. For instance, in the case of Interpretation, one has to resort to circumlocution to translate a source language (SL) item for which he/she has been able to find an appropriate equivalent in the target language (TL). Another example is the strategy of Omission. In this case, the person totally disregards one language item altogether in his/her work. (Dimitriu, 2004)

Second, Van Doorslaer (2007) himself contends that these inappropriate strategies are malfunctional in the sense that they would distort the intended message. Though Van Doorslaer does not point fingers to any of the strategies listed in his (2007) framework, some hints can be traced in the literature. For example, Krings (1986) found that advanced German learners of French had difficulty transmitting the meaning nuances, because they failed to choose the appropriate strategies for translating CSIs from French into German. Similarly, Klaudy and Károly (2005) contend that student translators would need to be instructed on strategies for CSIs as familiarity with strategies would increase the quality of their works.

Fortunately, Pope and Ouliaienia did not make use of any of these malfunctional strategies in their works. As you saw in Table 1 and Table 2, the strategies of Borrowing, Coinage, Paraphrase, Reformation, and Omission were used with zero frequency in the architectural textbooks targeted in the present study. This shows that Pope and Ouliaienia were successful in their own attempts to find appropriate equivalents for CSIs embedded in the targeted architectural textbooks.

The third research question of the study aimed to determine how frequently each of the used strategies was employed in the targeted architectural textbooks. As shown by Table 1, Pope mostly made use of the strategy of Interpretation. He used this strategy $46.25 \%$ of the times in his own Introducing Persian Architecture. This shows that Pope found the strategy of Interpretation more appropriate than other strategies nearly half of the times he encountered a CSI when writing Introducing Persian Architecture. Though it ranked second, the strategy of Interpretation was also used with high frequency, i.e., $31.42 \%$ of the times, in Abbasid Guest House from the Persian language into the English language. These results hint to the importance of this strategy, showing that writers/translators find it frequently necessary to slightly divert from/ make small changes to the original SL conceptualizations to be able to transfer the intended message to the TL readership.

The second strategy with the highest frequency in Pope's work was Domestication, being used $27.5 \%$ of the times in the case of CSIs in Introducing Persian Architecture. The strategy ranked third in Ouliaienia's translation of Abbasid Guest House as it was employed 20\% of the times in the translation of the CSIs in this book. Though there was a $7.5 \%$ difference between Pope and Ouliaienia in the use of this strategy, they made use of a significant amount of this strategy in their works. As you remember from before, Domestication is a strategy in which a transparent fluent style is adapted to minimize the strangeness of the SL conceptualization for the TL readership (Venuti, 1995, p. 20). In the case of architectural textbooks, the strangeness arises from the fact that a society's architecture is highly bound to its cultural patterns; therefore, its understanding may be difficult for people from other cultures. Therefore, one has to relieve the strangeness by using a more transparent style that is more readable for the TL readership. (See Armstrong, 2005; Venuti, 1995)

The significant difference between Pope and Ouliaienia was with respect to the strategy of Direct Transfer. The strategy was used $13.75 \%$ of the times in Pope's work whereas it was employed $35.28 \%$ of the times in Ouliaienia's work. As you remember, through Direct Transfer, the SL pattern is transferred directly to the TL. These results are supported by the findings of the previous study. Previous studies have found that Direct Transfer would be more useful, if the referent of the CSI belongs to the SL culture (e.g., Armstrong, 2005; Aziz, 1982; Krings, 1986; Maasoum \& Davtalab, 2011). In other words, because Ouliaienia embarked on translating from the Persian language (TL) into the English language (SL), he found it easy to trace direct equivalents in the TL, because the architectural textbook he translated was about Persian architecture that owned the cultural referents of the architectural terms in the SL textbook. The situation was completely reverse for Pope. In his work, Pope had to write in a language (i.e., the English language) which did not own the cultural referents of the CSIs of interest. According to Armstrong (2005), this makes finding equivalents for CSIs through Direct Transfer difficult, or inappropriate as was shown by the results of the present study.

Finally, the strategy of Word for Word Translation was the least used strategy in both works under investigation. The strategy was used $12.5 \%$ of the times in Pope's Introducing Persian Architecture and $14.28 \%$ of the times in Ouliaienia's Abbasid Guest House. Two interpretations can be presented for these results. First, the strategy of Word for Word Translation is of limited use in architectural texts. In other words, the use of Word for Word Translation would distort the message intended by a CSI embedded in an architectural text and, thus, the writer/translator would find it inappropriate to apply this strategy to CSIs. Second, Word for Word Translation is always used for stretches of words (i.e., more than one word) and its purpose is to maintain the structural originality of the SL text (Molina \& Hurtado Albir, 2002). The fact that Word for Word Translation is applied to stretches of words would highly limit its application, because most of the CSIs in the architectural textbooks investigated in the present study were represented by single words.

\section{Conclusion}

As mentioned earlier, architecture is a culture-loaded manifestation of particular people's traditions and behaviors at a particular time when the architectural designs were created (O'Shea, 1995; Rapoport, 2005). Further, architecture is not restricted to the setting in which it is created; that is, it both influences, and is influenced by, cultural patterns that are 
practiced in other societies (Bodard \& Evrard, 2011). The problem is that the architecture terminology in which the cultural patterns of a society are hidden is particular to that society (Terestyényi, 2011), meaning that rendering architecture terminology from one culture into another is a challenging task for translators and writers.

Seen in this way, translation of architecture terminology is of paramount importance when translating architectural texts from the source language into the target language. In fact, whenever translators are faced with culture specific items (CSIs), they have to make very important decisions that would influence the quality of their translation work. Of these decisions, the most important one is concerned with what strategy the translators should make use of to translate culture specific items (CSIs) in architectural texts. The purpose of the present study was to compare the quality and frequency of strategies used by a translator to translate an architectural text versus those used by a writer to write an architectural text on the Iranian architecture. Therefore, two architectural texts were selected for this purpose; i.e., Introducing Persian Architecture written by Pope in English and Hotel Abbasi written by Borjian and Borjian in Persian and translated into English as Abbasid Guest House by Ouliaienia.

The findings of the study indicated that the translator (Ouliaienia) and the writer (Pope) were successful in finding appropriate equivalents for SL architectural terms (Persian) in the TL (English). This finding was confirmed by the fact that Pope and Ouliaienia avoided using inappropriate strategies for CSIs related to Persian architecture. These strategies may distort the message intended; therefore, the message could not be completely transferred to the readership (Dimitriu, 2004; Krings, 1986). This risk is particularly high in the case of CSIs, because CSIs usually include cultural nuances that are of paramount significance to the message intended (Krings, 1986; Van Doorslaer, 2007).

A second purpose was to determine the most frequent strategies that the translator (Ouliaienia) and the writer (Pope), whose works were scrutinized in the present study, employed in their textbooks. Van Doorslaer's (2007) framework for classifying strategies was used as the basis for the analysis. However, the analysis was focused on only four of the strategies classified in Van Doorslaer's (2007) framework, as many of the other strategies in the framework are not usually selected in the case of CSIs, which was confirmed by a preliminary analysis of the targeted architectural textbooks. In fact, Van Doorslaer (2007) himself contends that the selection of strategies has an interplay with the genre of the field (e.g., architecture, arts, science, etc.) in which textbooks are written.

Therefore, the comparison of Pope's textbook and Ouliaienia's translation on the Persian architecture demonstrated that they had made use of four of the strategies classified in Van Doorslaer's (2007) framework. These four strategies were Direct Transfer, Word for Word Translation, Interpretation, and Domestication.

In the architectural textbooks investigated in this study, Pope and Ouliaienia made much use of the strategy of Interpretation, a strategy in which explicitly elaborates the shady differences between the SL and TL conceptualizations. This was followed by the strategy of Domestication in which a transparent fluent style is adapted to minimize the strangeness of the SL conceptualizations for the TL readership (Venuti, 1995, p. 20). The frequent use of these two strategies in the works investigated shows that the main aim of Pope and Ouliaienia has been to communicate the intended message (i.e., more focus on meaning) and they have less tried to remain faithful to the SL structures.

The difference between the two textbooks analyzed was observed with respect to the use of the strategy of Direct Transfer. While Direct Transfer was the most frequently used strategy in Ouliaienia's work, the strategy ranked third in Pope's work. This finding was interpreted through the proposition that Direct Transfer will be more useful when the cultural referent of the CSI belongs to the SL culture (e.g., Armstrong, 2005; Aziz, 1982; Krings, 1986). Therefore, Ouliaienia made more use of the strategy of Direct Transfer in his translation from the Persian language into the English language, because the Persian language owned the cultural referents of the architectural terms in the SL textbook. On the other hand, Pope had to write in the English language that did not own the cultural referents of the CSIs of interest.

Word for Word Translation was the least used strategy in Pope's and Ouliaienia's works. Therefore, it could be discussed that Word for Word Translation is of limited use in writing and translating architectural texts as it may distort the message intended by CSIs. In addition, the strategy is most used for stretches of words to maintain the originality of the targeted structures (Molina \& Hurtado Albir, 2002). Thus, such limited use constrained the application of Word for Word Translation, because most of the CSIs in the architectural textbooks investigated in the study were embedded in single words.

The findings of the present study have significant implications for translation theory and practice. As far as their implications for translation theorizing are concerned, the findings of the study suggest that the selection of strategies used for lexical items in the area of architecture may be influenced by decisions different from those decisions driving the selection of strategies for other types of language genres. Thus, any translation theory should take into account the variations in the selection of strategies that arise from the genre types. These variations become a factor particularly when the translation of CSIs is the issue (See Munday, 2001).

Further, translation theoreticians should provide explanations as to why translators of texts of different genres would prefer the use of particular translation strategies over others. Though such explanations needs the further step of investigating the cognitive processes that writers/translators use when choosing particular strategies, the step would ultimately bear fruitful outcomes for a comprehensive theory (see Göpferich, Jakobsen, \& Mees, 2009 for a collection of papers on cognitive translation processes). In fact, the step has been already taken by several scholars (e.g., Asadi \& Séguinot, 2005; Jakobsen, 2003). 
As far as their implications for practice are concerned, the range of implications of the findings is even wider. In fact, the implications of the findings for practice can be in the areas of corpus linguistics, translation training, and development of translation skills. For corpus linguistics, one suggestion in the field is that bilingual dictionaries of terms can be prepared based on the analysis of the appropriate and most frequent equivalents used by writers and translators in their works (Baker, 1995, 1996). Therefore, the same can be done with respect to architectural terminology. Though such dictionaries cannot be prepared based on single studies, or a limited number of studies, the present study paves the way for future ones, resulting in more findings based on which the dictionaries can be prepared.

As far as the implications of the findings for translation training are concerned, one implication could be that instructors should teach their student on the appropriate strategies for CSIs. More particularly, the instructors should make their students aware that the use of inappropriate strategies may distort the intended message (Fawcett, 1981; Hatim, 2014). These hints would ultimately result in the development of good translation skills in students.

Research in social sciences and humanities, including Translation Studies, is a continuous process (Dunne, Pryor, \& Yates, 2005; Lodico, Spaulding, \& Voegtle, 2006) as it is rather impossible to reach conclusive answers to research questions based on findings of just one study. The research attempt undertaken in the present study can be followed in several directions in future studies. First, it is suggested that the present study be replicated on more architectural texts written and translated by other writers/translators to see whether the findings obtained can be generalized to a wider range of such texts (Alves, 2003). Therefore, till such studies are undertaken by other researchers in future, the generalizability of the findings is restricted to the architectural texts targeted in this study.

Second, as mentioned before, study of strategies used to write/translate CSIs would give us an incomplete picture if we do not take into account why the writers/translator chooses some particular strategies over others. That is, researchers should look into the cognitive processes that drive the use of strategies for CSIs. Think-aloud protocols are particularly helpful for this purpose (Bernardini, 2002; Bowles, 2010; Gerloff, 1986). In a think-aloud protocol, the writer/translator would talk about his/her choice of strategies simultaneously as he/she is writing/translating, letting the researcher look into the cognitive processes driving the selection of strategies. (Bernardini, 2002)

Third, it is recommended that studies of similar type be carried based on other frameworks and models. Even though Van Doorslaer's (2007) framework that was employed in the present study has been one of the most used frameworks in the recent years, the framework has not yet been validated. Therefore, it is necessary to carry out studies of similar type based on other frameworks and models to see whether the findings obtained in the present study would be repeated if the new frameworks and models were adopted.

Finally, researchers are recommended to undertake comparative studies on CSIs within different genre types. Although architectural texts are good examples of culturally-loaded language materials they are not the only language texts with this feature. Among others, literary texts, commercial labels, product mottos, etc. are other tools by which cultural representations are transmitted to the readership. It would give us fruitful result if we could determine whether translators make use of strategies different those usually used in the translation of architectural texts.

\section{References}

Aixela, J. F. (1996). Culture-specific items in translation. In R. Alvarez \& M. Carmen-Africa Vidal (Eds.), Translation, power, subversion (pp. 52-78). Clevedon: Multilingual Matters.

Alves, F. (2003). Triangulating translation: Perspectives in process oriented research. Amsterdam: John Benjamins. Armstrong, N. (2005). Translation, linguistic, culture: A French- English handbook. Clevedon: Multilingual Matters.

Asadi, P., \& Séguinot, C. (2005). Shortcuts, strategies, and general patterns in a process study of nine professionals. Meta, 50(2), 522-547.

Aziz, Y. Y. (1982). Cultural Problems of English-Arabic Translation. Babel, International Journal of Translation, 28(1), 25-29.

Baker, M. (1992). In Other Words: A Course Book on Translation. London: Routledge.

Baker, M. (1995). Corpora in translation studies: An overview and some suggestions for future research. Target, 7(2), 223-243.

Baker, M. (1996). In Other Words: A Course Book on Translation. London: Routledge.

Bodard, M. \& Evrard, A. (2011). Architecture \& Sustainable Development (Vol.2): 27th International Conference on Passive and Low Energy Architecture. De Louvain: Pressese University.

Borjian, H. \& Borjian, H. (1997/1376). Hotel Abbasi. Tehran: Bimey-e Iran.

Bowles, M. A. (2010). The think-aloud controversy in second language research. London: Routledge.

Ching, D. K. (2011). A Visual Dictionary of architecture. USA, New Jersey: Wiley.

Dimitriu, R. (2004). Omission in translation. Perspectives: Studies in Translatology, 12(3), 163-175.

Dunne, M., Pryor, J., \& Yates, P. (2005). Becoming a Researcher: A Research Companion for the Social Sciences: A Companion to the Research Process. McGraw-Hill Education (UK).

Fawcett, P. (1981). Teaching translation theory. Meta, 26(2), 141-147. 
Gambier, Y. (2004). Doubts and Directions in Translation Studies. The Netherlands: John Benjamins.

Gerloff, P. (1986). Second language learners' reports on the interpretive process: Talk-aloud protocols of translation. In House, J. and S. Blum-Kulka (eds.) Interlingual and intercultural communication. Tubingen: Gunter Narr.

Ghobadi, M. (2013).Translation and Symbolism in Drama: Four Case Studies of W. B. Yeats's Plays. In Translation Journal, 17, 3. Retrieved from http://translationjournal.net /journal/65yeats.htm.

Göpferich, S., Jakobsen, A. L. \& Mees, I. M. (Eds.) (2009). Behind the mind: Methods, models and results in translation process research. Copenhagen: Samfundslitteratur Press.

Hatim, B. (2014). Teaching and researching translation. London: Routledge.

House, J. (2009). Translation. Oxford \& New York, Oxford University Press.

Jakobsen, A. L. (2003). Effects of think aloud on translation speed, revision and segmentation. In F. Alves (Ed.), Triangulating translation: Perspectives in process oriented research (pp. 69-95). Amsterdam \& Philadelphia: John Benjamins.

Klaudy, K., \& Károly, K. (2005). Implicitation in translation: Empirical evidence for operational asymmetry in translation. Across Languages and Cultures, 6(1), 13-28.

Krings, H. P. (1986). Translation problems and translation strategies of advanced German learners of French. In J. House, \& S. Blum-Kulka (Eds.), Interlingual and intercultural communication (pp. 263-75). Tubingen: Gunter Narr.

Kwiecinski, P. (1998). Translation strategies in a rapidly transforming culture: A Central European perspective. The Translator, 4(2), 183-206.

Lodico, M. G., Spaulding, D. T., \& Voegtle, K. H. (2006). Methods in educational research: From theory to practice. San Francisco: Jossey-Bass Publishers.

Maasoum, S. M. H., \& Davtalab, H. (2011). An Analysis of Culture-specific Items in the Persian Translation of “Dubliners" Based on Newmark's Model. Theory and Practice in Language Studies, 1(12), 1767-1779.

Rafiee Sereshki, B., Rafizade, N., Ranjbar Kermani, M. (2007/1386). Farhang-e Mehrazi [Mehrazi Dictionary]. Tehran: Markeze Tahghighate Saxteman va Maskan.

Molina, L., \& Hurtado Albir, A. (2002). Translation techniques revisited: A dynamic and functionalist approach. Meta: Journal des traducteurs/ Meta: Translators' Journal, 47(4), 498-512.

Munday, J. (2001). Introducing translation studies: Theories and application. New York: Routledge.

Newmark, P. (1995). Paragraphs on Translation. Clevedon/Philadelphia /Adelaide: Multilingual Matters Ltd.

O'Shea, C. E. (1995). Culture, Symbol and Time: the Revitalization of Samarkand. (MA Thesis). Retrieved from Massachusetts Institute of Technology: Dept. of Architecture, USA. Retrieved from http://hdl.handle.net/1721.1/70249.

Ouliaienia, H. (1997). Abbasid Guest House. Tehran: Bimey-e Iran.

Pope, A. P. (1956). Introducing Persian Architecture. London: Thames and Hudson.

Rapoport, A. (2005). Culture, architecture, and design. Chicago: Locke Science Publishing Company.

Sadri Afshar (2011/1390). Memorize Iran [Persian translation of Introducing Persian Architecture by Arthur Upham Pope (1956)]. Tehran: Farhangian Publication.

Terestyényi, E. (2011). Translating Culture-specific Items in Tourism Brochures. Budapest Business School College of Commerce, Catering and Tourism Department of Languages for Specific Purposes Hungary. Retrieved from http:// www. skase.sk/Volumes /JTI06/pdf_doc/02.pdf.

Van Doorslaer, L. (2007). Risking Conceptual Maps. In Y. Gambier \& L. Van Doorslaer (Eds.), The Metalanguage of Translation (pp. 217-233). The Special Issue of Target, 19, 2.

Venuti, L. (1995). The translator's invisibility: A history of translation. London \& New York: Routledge.

Vinay, J. \& Darbelnet, J. (1997). A Comparative Stylistics of French and English: A Methodology for Translation. In J. Munday (Ed.), Introducing Translation Studies: Theories and Application. London \& New York: Routledge. 